Frank Leinen

(Düsseldorf)

\title{
PACO IGNACIO TAIBO II \\ UND DIE MEXIKANISIERUNG DES KRIMINALROMANS. INTERKULTURELLE SPIELFORMEN DER NUEVA NOVELA POLICÍACA ZWISCHEN FAKT UND FIKTION
}

Anfang der siebziger Jahre, so wird kolportiert, kursierten in Kreisen konservativer Literaturhistoriker die folgenden, nicht ganz ernst gemeinten Fragen: »Was tut ein seriöser Literaturforscher? «»Er interpretiert romantische Lyrik. « - Was tun zwei seriöse Literaturforscher? «»Sie bereiten eine neue Barockedition vor.« - »Und was tun drei seriöse Literaturforscher? « »Drei seriöse Forscher gibt es nicht mehr. Einer von ihnen beschäftigt sich mit Trivialliteratur. « ${ }^{1}$ Der Witz besitzt inzwischen historischen Wert, denn populäre Literaturformen wie der Kriminalroman genießen seit über zwei Jahrzehnten in Europa und den USA eine breite wissenschaftliche Akzeptanz. Diese Tatsache darf freilich nicht darüber hinwegtäuschen, dass es etliche Jahre dauerte, bis sich in der Forschung die Einsicht durchgesetzt hatte, dass populäre Kriminalliteratur nicht unbedingt anspruchslos sein muss.

Schon im Jahr 1972 stellte Edgar Marsch in Anlehnung an Gerhard Schmidt-Henkel fest, dass eine Zuordnung qualitativ schlechter Romane zu weniger gebildeten Leserschichten nicht zulässig und der Kriminalroman weder sprachlich noch in der Figurendarstellung, noch im Handlungsaufbau eindeutig strivial sei. $^{2}$ Zwar wuchs im europäischen und nordamerikanischen Raum seit den frühen siebziger Jahren allmählich die Bereitschaft, dem Kriminalroman literarische Qualitäten zuzugestehen, doch tendierte auch die Forschung späterer Jahre dazu, zumindest die schematische Bauform der Gattung als Mangel anzusehen. ${ }^{3}$ Thomas Narcejac beklagte daher im Jahr 1975 aufgrund der aus seiner Sicht allzu schleppenden Anerkennung des Kriminalromans, dass das Genre immer noch den Makel der Para-

Viktor Žmegač (1971: 7).

Edgar Marsch (1972: 59).

Cf. Ulrike Landfester (1990: 415). 
literatur trage. ${ }^{4}$ Eine Gegenposition vertrat im gleichen Jahr für die deutschsprachige Romanistik Ulrich Schulz-Buschhaus, der seine Untersuchung zu Formen und Ideologien des Kriminalromans mit der apodiktischen Aussage eröffnete, die Beschäftigung mit der sogenannten Trivialliteratur sei inzwischen zu einer Selbstverständlichkeit geworden. ${ }^{5}$

Im Laufe der hier nur in groben Zügen skizzierten Entwicklung wandelte sich auch der Begriffsgebrauch, und der auf eine vermeintliche qualitative Minderwertigkeit abzielende Terminus > Trivialliteratur $<$ wurde durch den werturteilsfreieren Begriff der >Populärliteratur` abgelöst. ${ }^{6}$ Mittlerweile zählt die Beschäftigung mit Werken der populären Kriminalliteratur zum universitären Standard, und ihre Bedeutung für den fremdsprachlichen Schulunterricht ist seit den siebziger Jahren unumstritten. ${ }^{7}$ Nach langen Debatten erkannte man in der europäischen Literaturkritik, zuletzt im postfranquistischen Spanien $^{8}$, den Kriminalroman als ernst zu nehmendes Thema an.

In Hispanoamerika hingegen erfolgte mit Ausnahme Kubas und Argentiniens die literaturtheoretische und -kritische Auseinandersetzung mit der novela policiaca bislang vergleichsweise zurückhaltend. So dominieren bis in die Gegenwart hinsichtlich der Theoriebildung zum Kriminalroman Stellungnahmen von nicht-hispanoamerikanischen Wissenschaftlern, welche fast ausschließlich französische oder englischsprachige Texte zum Gegenstand haben. Roger Caillois, Tzvetan Todorov, Edmund Wilson, Dennis Porter, Umberto Eco, Jacques Lacan oder Roland Barthes seien stellvertretend genannt. Für die in Hispanoamerika vorherrschende Ablehnung des Genres kann beispielhaft ein Urteil Ernesto Sábatos zitiert werden. Dem Argentinier, der bekanntlich seine Werke als literarische Experimente konzipierte, war der traditionelle Kriminalroman ein Gräuel:

En general, nadie lo toma en serio: ni el literato que lo fabrica - por algo se pone seudónimo - ni el editor que lo industrializa, ni el lector que lo consume. Con razón esta literatura la leen los negociantes cansados que viajan en avión. ${ }^{9}$

4 Thomas Narcejac (1975: 15)

5 Ulrich Schulz-Buschhaus (1975: VII).

6 Beispielhaft für diese Entwicklung steht Hans-Jörg Neuschäfer (1976).

7 Cf. Dietmar Fricke (1977).

8 Den Nexus zwischen politischen Rahmenbedingungen und literarischen Innovationen des spanischen Kriminalromans erschließt José F. Colmeiro (1992).

9 Ernesto Sábato (1973: 126). 
Entsprechend dieser Grundeinstellung ließen sich jenseits des Atlantiks nur wenige Stimmen vernehmen, die sich ernsthaft und differenzierend mit der Gattung auseinander setzten. Meist ging dabei das schriftstellerische mit dem literaturkritischen Engagement Hand in Hand. An prominenter Stelle ist sicherlich Borges zu nennen, der freilich den Blick nach Osten gerichtet hielt und sich besonders intensiv mit Poe, Chesterton, Van Dime und Dorothy Sayers beschäftigte. Hinweise auf hispanoamerikanische Autoren sucht man in seinen kritischen Schriften vergebens. Ihm dient wie auch seinem Ko-Autor Adolfo Bioy Casares die Kritik am europäischen pointierten Rätselroman dazu, der eigenen Konzeption eines gelungenen, psychologisch fundierten, nicht aber von einer positivistischen Wissenschaftsemphase getragenen Kriminalromans theoretisches Profil zu verleihen. ${ }^{10}$

Auf mexikanischer Seite befassten sich namentlich Alfonso Reyes und Carlos Monsiváis mit dem Kriminalroman. Mag angesichts der neohellenistischen kulturphilosophischen und literarästhetischen Ideale des erstgenannten die Beschäftigung mit der Gattung zunächst erstaunen, so scheint sie bei dem letzteren als Theoretiker der Populärkultur eher auf der Hand zu liegen. Reyes kommt schon 1945 unter Anerkennung der Tatsache, dass der Kriminalroman das jüngste und im Hinblick auf die Leserzahlen erfolgreichste Genre der Gegenwart darstellt, zu dem Schluss:

Interés de la fábula y coherencia en la acción. Pues ¿qué más exigía Aristóteles? La novela policial es el género clásico de nuestro tiempo. ${ }^{11}$

Dem wäre hinzuzufügen, dass Aristoteles auch den Mord, vor allem innerhalb einer Familie, als besonders wirkungsvolles dramatisches Mittel hervorhebt, das Jammern und Schaudern bewirke. ${ }^{12}$ Zur hispanoamerikanischen Kriminalliteratur äußert sich der Essayist nur punktuell, denn allein Borges und Bioy Casares finden Beachtung:

$[\mathrm{H}]$ ay mil notas y luminosos atisbos en Jorge Luis Borges, que, en colaboración con Adolfo Bioy, está dando carta de naturalización al género en la literatura hispanoamericana y, podemos decir, en la hispana. ${ }^{13}$

10 Siehe Ulrich Schulz-Buschhaus (1991).

11 Alfonso Reyes (1959: 461). Siehe ferner id. (1989:412-417), sowie id. (1989:417-420).

12 Aristoteles (1994: 43).

13 Alfonso Reyes (1959: 458). 
Die von den beiden Argentiniern mittels der Transkulturation realisierte Umsetzung universalistischer Theoreme weckt die besondere Aufmerksamkeit des ehemaligen Mitgründers des Ateneo de la Juventud. Die Entwicklung eines hispanoamerikanischen Kriminalromans auf der Grundlage des Fremden erscheint ihm als gangbarer Weg zu einer eigenständigen Literaturform, welche die Emanzipation von der kulturellen Dominanz Europas fortschreiben und zugleich die Attraktivität des universalistisch geprägten Eigenen demonstrieren soll.

Während der als Neoklassizist bekannte Reyes dem populären Kriminalroman eine Lanze bricht, äußert sich ausgerechnet einer der prominentesten Propagandisten der mexikanischen Populärkultur, Carlos Monsiváis, sehr zurückhaltend, wenn nicht gar ablehnend, zur mexikanischen Ausgestaltung des Genres. Monsiváis' Interesse gilt insbesondere dem Kriminalroman des anglophonen Raumes; den mexikanischen Beitrag zur Gattung erfasst er mit einem vernichtenden Urteil, das keinen Zweifel daran lässt, wie sehr seiner Meinung nach das von Reyes eingeforderte Projekt mangels Originalität gescheitert ist:

Por lo general, la práctica mexicana de la literatura policial ha sido imitativa, arbitraria, forzada. Los cultivadores parecen escasos [...] y no demasiado convincentes. Una conclusión: en México no hay ni parece probable que exista la novela policial o literatura de complots y espionaje. ${ }^{14}$

Trotz der in der hispanoamerikanischen Öffentlichkeit verbreiteten Skepsis gegenüber dem Kriminalroman ist die Literaturkritik auch jenseits des Atlantiks durchaus bereit, seine Bedeutung als Ideenlieferant für den modernen und postmodernen hispanoamerikanischen Roman zu würdigen. So greifen Jorge Luis Borges, Adolfo Bioy Casares, Gabriel García Márquez, Mempo Giardinelli, Jorge Ibargüengoitia, Manuel Peyrou, Manuel Puig, Ernesto Sábato, Mario Vargas Llosa oder Vicente Leñero sowohl auf der Ebene der histoire als auch des discours Elemente des Kriminalromans auf, um das Spannungsinteresse ihrer Werke zu fördern. Die hispanoamerikanischen Autoren scheinen somit durchaus bereit, das Genre im Sinne Genettes als hypotextuelle Folie zu akzeptieren, da sie erkannt haben, wie intensiv beispielswiese ihre Darstellung einer vom Evidenzverlust gekennzeichneten labyrinthischen Existenz oder ihre narrativen Experimente aus

14 Carlos Monsiváis (1973: 11). 
dem Ideen- und Formenreservoir des Kriminalromans zu schöpfen vermögen. Demgegenüber finden sich jedoch nur wenige hispanoamerikanische Autoren, die sich der Kriminalliteratur verschrieben haben.

Auch in wissenschaftlicher Hinsicht ist der hispanoamerikanische Kriminalroman als eigenständige und eigenwertige Gattung im Unterschied zu dem spanischen Kriminalroman ${ }^{15}$ bislang weitestgehend eine terra incognita geblieben. Gleichwohl weisen die seit dem letzten Jahrzehnt vor allem außerhalb Hispanoamerikas erschienenen Überblicksmonographien und spezialisierten Publikationen auf ein wachsendes Forschungsinteresse hin. ${ }^{16}$ Diese Entwicklung wurde sicherlich durch die seit den sechziger Jahren nachvollziehbare Aufwertung der Massenkultur und Massenkommunikation sowie die Internationalisierung und Hybridisierung des hispanoamerikanischen Literatur- und Kulturbetriebs nachhaltig gefördert. ${ }^{17}$

Auf den folgenden Seiten möchte ich die von Monsiváis zu Anfang der siebziger Jahre artikulierte skeptische Sicht zumindest für den zeitgenössischen mexikanischen Kriminalroman in Frage stellen. Es soll dargelegt werden, wie der derzeit rührigste Kriminalautor des Landes, Paco Ignacio Taibo II, im Sinne einer Mexikanisierung des Kriminalromans internationale literarische Paradigmen im intertextuellen Spiel den spezifischen Bedürfnissen der mexikanischen Kultur entsprechend in seine Romane einschreibt. Hiermit zusammenhängend wird alternativ zur Erforschung der Bedeutung des Kriminalromans für die postmoderne Erzählprosa die Frage nach den Einflüssen neuerer literarästhetischer Tendenzen auf die postmoderne Kriminalliteratur gestellt. Ein derartiger Blickwinkel könnte dazu beitragen, die häufig einseitige Perspektivierung des Kriminalromans als Ideenlieferant für andere Genera zu relativieren und die dichten intertextuellen sowie interkulturellen Bezüge zwischen den verschiedenen Literaturformen in den Vordergrund zu stellen. Die kulturell vermittelten und ver-

15 Cf. die Beiträge von Albrecht Buschmann, Hartmut Stenzel und Jürgen Sieß in: Dieter Ingenschay / Hans-Jörg Neuschäfer (1991: 168-191). Vor allem die Romane Manuel Vázquez Montalbáns und die Traditionslinie des postfranquistischen Kriminalromans als Fortschreibung der novela social erwecken besondere Aufmerksamkeit. Siehe Víctor Claudín (1985). Juan José Plans behandelt in seiner »Historia de la novela policíaca « (1969) ausnahmslos französische und englischsprachige Autoren. Auch César E. Díaz (1973) erfasst in seinem Handbuch fast ausschließlich die englische, nordamerikanische und französische Produktion. Der resto del mundo wird auf nur 14 Seiten abgehandelt.

16 Siehe zum mexikanischen Kriminalroman Cynthia Duncan (1991); Mari Paz Balibrea Enríquez (1996); Eugenia Revueltas (1987); Amelia S. Simpson (1990); Ilán Stavans (1993) und Vicente Francisco Torres (1985).

17 Cf. Reinhold Görling (1997: 167) und Ottmar Ette (1994). 
mittelnden Eigenschaften des Kriminalromans als Schaltstelle - oder SpielRaum - einer Begegnung von Eigenem und Fremdem vermögen dabei jene trans- und rekontextualisierenden Assimilationsprozesse zu illustrieren, welche durch den von Rama in die Diskussion gebrachten Begriff der transculturación und ihre Elemente selección, desculturación, incorporación, invención und recomposición erfasst werden. ${ }^{18}$ Kritische Distanz zum Eigenen und ästhetisch reflektierte Transkulturation des Fremden sind die Pole, aus denen Taibos Kriminalromane ihre spannungsgeladene Energie und literarische Qualität ableiten. Die exemplarische Analyse des Romanschaffens Taibos soll zu erkennen geben, wie der Autor durch seine Mexikanisierung des Genres parodistisch und (selbst-)ironisch, bisweilen karikaturesk, Kritik an den gesellschaftlichen Verhältnissen übt. Da die Regierungspartei PRI seit über fünfzig Jahren versucht, den Kulturbetrieb des Landes mit dem Ziel der Herrschaftssicherung möglichst weitreichend unter ihre Kontrolle zu bringen, trifft Taibos politisch oppositioneller Impetus, der mit dem literarischen Projekt einer Internationalisierung und Hybridisierung der mexikanischen Kultur einhergeht, auf massiven Widerstand:

La crítica en México no se pretende como puente entre los autores y los lectores. La crítica en México se pretende como juez de quién tiene derecho a ser escritor o quién no, como propietaria del espacio cultural, y en esa medida, a alguien como yo que soy un impulsor desde el marginalismo, obviamente se me niega el derecho a pertenecer a esos espacios culturales sistemáticamente. ${ }^{19}$

Die von Taibo bestätigte Offizialisierung der literarischen Kultur fördert die in der mexikanischen Literaturkritik nachvollziehbare Entwicklung einer problematischen Dichotomie von vermeintlich anspruchsvoller, erhabener literatura dificil und vorgeblich niederer, weil leicht konsumierbarer literatura light. Taibos Entscheidung, Kriminalromane zu verfassen, bedeutet angesichts dieser Gegebenheiten eine willentliche Marginalisierung, welche ihm zugleich jene literarischen und ideologischen Freiräume eröffnet, die er in seinen Werken ausloten möchte.

Mit Dias de combate ${ }^{20}$ wandte sich der 1949 im spanischen Gijón geborene, seit 1958 in Mexiko lebende und 1980 eingebürgerte Taibo 1976 der Kriminalliteratur zu. Inzwischen liegen über vierzig Bücher von ihm

18 Ángel Rama (1982: 38).

19 Interview mit Juan C. Ramírez / Verónica Rodríguez Sifontes (1992: 47).

20 Mexiko: Grijalbo, 1976. 
vor, und er gilt mit als einer der meistgelesenen mexikanischen Kriminalautoren der Gegenwart. Die Werke Taibos werden in 25 Ländern und in 12 Sprachen publiziert; drei seiner Romane kürte die New York Times zum Buch des Jahres, und die ansonsten in ihren Äußerungen eher zurückhaltende Le Monde ließ sich gar zu dem Ausruf »Viva Paco ${ }^{21}$ hinreißen. Taibo erhielt unter anderem 1982 den Premio Grijalbo für Héroes convocados ${ }^{22}$ und 1992 den Premio Planeta für La lejanía del tesoro ${ }^{23} .1987$ wählte man ihn zum Präsidenten der über 2000 Autoren vereinigenden International Crime Writer Association. In demselben Jahr wurde ihm von dieser Vereinigung erstmals der Hammett-Preis für La vida misma ${ }^{24}$ verliehen. 1991 erhielt Taibo die gleiche Ehrung für Cuatro manos ${ }^{25}$.

Taibos vielfältige außerliterarische Aktivitäten geben Aufschluss über sein Bestreben, eine Position am Rande der gesellschaftlichen Konventionen zu suchen. Nach seinem Studium an der UNAM und seiner Mitwirkung an der Studentenbewegung von 1968 wirkte er als profesor de historia del movimiento obrero. Er betätigte sich als engagierter Verfasser historischer und politikwissenschaftlicher Studien sowie als kritischer Journalist. Wie sehr auch seine Romanwerke von oppositionellen politischen Überzeugungen getragen werden, dokumentiert schon die Auswahl seiner zahlreichen Epigraphen. Sie zitieren neben Goethe, der Bibel oder Chandler auch Engels, Proudhon, Hegel, Nietzsche, Trotzki, Sartre, Brecht und Böll. Als Mitglied des PRD wirkte Taibo als Berater Cuauhtémoc Cárdenas' in kulturellen Angelegenheiten.

Da die mexikanische Literaturkritik geflissentlich über ihn hinwegsieht ${ }^{26}$, präsentiert sich Taibo gerne als marginalisierter David, der gegen den Goliath der literarischen Nationalkultur antritt. Deshalb pflegt er regelrecht seine Feindschaft gegenüber der »banda de oportunistas a la espera de prebendas, poder político cultural, ascenso en las mafias y posibilidad de encadenarse a los caballos vencedores de estos grupos de mafias $\aleph^{27}$. Mit bissigem Grimm freut sich Taibo immer wieder, dass seine Kriminalroma-

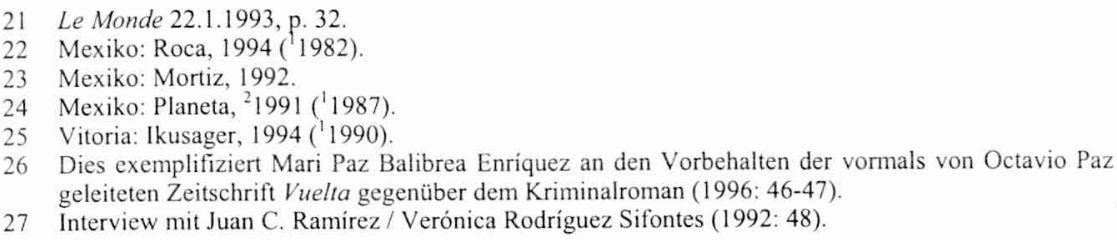


ne als pelo en la sopa der »kulturellen Mafia« die Freude am nationalliterarischen Eintopf verderben. Als schreibender ciudadano de la venganza organizada, der seine Romane als »ajuste de cuentas contra el sistema« konzipiert $^{28}$, verbindet sich Taibos Vertrauen in die emanzipatorischen Fähigkeiten des Volkes mit dem Bestreben, das Ausmaß der politischen Korruption in Mexiko zu enthüllen. Dem Horrorbild eines allmächtigen Staates stellt der Schriftsteller dabei das Ideal einer offenen, pluralen und sozial gerechten Gesellschaft entgegen, in der die Verletzlichkeit dem Anderen gegenüber und die Solidarität die höchsten Werte bilden. ${ }^{29}$ Der mexikanische Staat droht seiner Meinung nach zum Moloch zu werden:

Mientras no logremos romper dicha idea no lograremos transformar este país, sobre todo los hábitos creados por toda una casta de políticos sabedores que como ciudadanos no valen un centavo, que como profesionales no tienen ni idea y que no podrían sobrevivir en una sociedad normal, por lo que su única supervivencia está ligada al uso fraudulento del control del poder, que les permite la riqueza inmediata, el abuso, etc., lo cual también les norma la economía, porque a través del uso del poder negocian y regulan toda su vida económica. Este amafiamiento que relaciona negocio, poder, control, abuso, hay que romperlo, ya que forma parte de las costumbres de las capas políticas mexicanas. ${ }^{30}$

Der wiederholte Verweis auf das mafiöse mexikanische System macht deutlich, welches Selbstverständnis Taibo umhertreibt: Er sieht sich als Einzelkämpfer gegen das System, als eine Art sozialistischer Robin Hood der mexikanischen Literatur.

Wie für die Repräsentanten der Onda sowie der novela testimonial verbinden sich auch für Taibo mit der »parteaguas de la historia mexicana

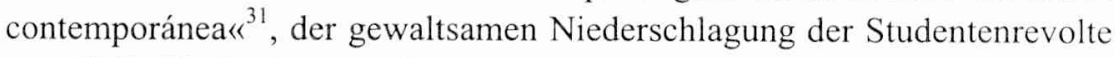
von 1968, Eindrücke, welche sein gesellschaftliches und schriftstellerisches Engagement entscheidend prägten. In diesem Sinne bietet sich der Blick auf seinen Roman Héroes convocados ${ }^{32}$ an, den Taibo nach der Nieder-

28 So Taibo im Gespräch mit José Tlatelpas (1997).

29 In einem Interview meint Taibo hierzu: "Prefiero la palabra tolerancia en su acepción moderna: tolerar, permitir, aceptar. Pero creo que debemos ir hacia una sociedad en la cual el elemento fundamental sea el descubrimiento de que los otros son nosotros, y de que las diferencias son las que nos enriquecen, no las igualdades«, in: Martín Corona (1998). In einem in Deutschland aufgezeichneten Gespräch meint der Schriftsteller: „Der Staat glaubt von sich, daß er ewig sei. Aber das ist falsch. Der einzig ewige Wert ist die Solidarität«, in: Albert Sterr (1997).

30 In: Martin Corona (1998).

31 José Luis Martínez / Christopher Domínguez Michael (1995: 222).

32 Verweise auf die verwendete Textausgabe werden im Weiteren durch Angabe der Sigle HC vorgenommen. 
schlagung des Aufstandes verfasste, um die deprimierende Erfahrung der politischen Niederlage und den Verlust der gesellschaftlichen Ideale zu verarbeiten. Der fiktionale Rückblick auf die eigenen Versäumnisse lässt ihn ein Manual para la toma del poder, so der Untertitel, erstellen. Taibo legt einen mit einer Prise bitterer Selbstironie gewürzten Roman vor, der Zutaten aus der experimentellen Literatur mit Elementen der dokumentarischen Zeugnisliteratur, wie wir ihr bei Poniatowska und Monsiváis begegnen, mischt. Hinzu kommt die in einer wirklichkeitsnahen Umgangssprache realisierte Erfassung des Lebensgefühls junger Mexikaner und ihrer urbanen Gegenwartskultur, welche Taibo mit den Autoren der Onda verbindet.

Ohne dass Héroes convocados ein Kriminalroman ist, schreibt Taibo in ihm mit dem Ziel einer Verrätselung der Handlung textuelle Techniken ein, die auf seine Kriminalproduktion verweisen. So montiert der Autor collageartig die fiktive Erzählhandlung mit polyphonen, Authentizität suggerierenden Dokumenten. Hiermit einher geht eine Zweiteilung der Zeitebenen. Die chronologische Rekonstruktion lässt erkennen, dass die Zeitebene der Dokumentation auf die Zeitebene der Erzählung folgt. Im Romanverlauf selbst sind beide Zeitebenen jedoch parallel geschaltet. Durch die Kombination beider Ebenen entwickelt sich zwischen ihnen durch den rekonstruierenden Nachvollzug eine sinnstiftende Wechselbeziehung. So erschließt der Aufklärung wünschende, idealerweise mit detektivischem Erkenntnisdrang ausgestattete Leser, dass die Hauptfigur, der ehemalige Student Néstor, Ende 1969 über längere Zeit hinweg in einem Krankenhaus behandelt wurde. Aufgrund seiner kommunistischen Überzeugungen hatte er an dem Studentenaufstand teilgenommen, und er musste nach dessen Niederschlagung gemeinsam mit den Studienfreunden zusehen, wie der allmächtige Staat jegliche Opposition gewaltsam unterdrückte und die Unterwanderung der Universität durch kriminelle Elemente tolerierte oder sogar förderte. Der nach 1968 als Journalist tätige Néstor wurde zur Behandlung eingeliefert, weil ihn ein mataputas während eines Interviews mit einem Messer lebensgefährlich verletzt hatte. Unter dem Einfluss von Medikamenten, zeitweilig in einem Schwebezustand zwischen Traum und Wirklichkeit, fasst der am Rande des Todes stehende Protagonist den Beschluss, einen neuen Aufstand gegen den Staatspräsidenten Díaz Ordaz ins Leben zu rufen. Seine Erzählung erhält fortan einen surrealen Charakter, welche die Grenzziehung zwischen Realität und Traum unmöglich macht. 
Der von Fieber geplagte Néstor entwickelt den Plan, dass nicht mehr die Studenten Träger der neuen Erhebung sein sollen, sondern populäre Heldenfiguren aus der Literatur. Deshalb sendet er Telegramme in alle Welt, um diese Helden nach Mexiko zu bitten: Sandokan und die Malaiischen Tiger, Sherlock Holmes, der auf ausdrücklichen Wunsch Néstors seinen ungeschickten Assistenten Watson in England lässt, die Drei Musketiere, Winnetou und Old Shatterhand, Wyatt Earp, Doc Holliday und sogar ein Nachfahre des Hundes von Baskerville bilden die wesentlichen Stützen des von Néstor zusammengestellten Ejército de la Reconquista. Der erste Höhepunkt der für die Polizei und das Militär blutigen Auseinandersetzung mit den héroes convocados wird erreicht, als der Zögling des Hundes von Baskerville seine doppelten Zahnreihen in den Hals des Staatspräsidenten gräbt. Nach einem derartig effektiven Auftakt strömen sodann nicht weniger als 400.000 Studenten durch die Avenida Juárez, und im ganzen Land kommt es zu einem Aufstand der Ausgebeuteten. Auch der General, der 1968 auf der Plaza de las Tres Culturas ohne Vorwarnung auf die Studenten schießen ließ, verliert sein Leben; die Revolution geht schließlich über in ein Volksfest, ist aber noch nicht beendet, als Néstor das Krankenhaus verlässt, um vorübergehend nach Casablanca zu verreisen. Im Hinblick auf die von dieser Romanebene ausgehende Botschaft steht Héroes convocados für die Überzeugung Taibos, dass die Phantasie und ihre literarische Verarbeitung effektive Widerstandspotentiale gegen den staatlichen Autoritarismus entwickeln können.

Dem bisher geschilderten skurril-surrealen Geschehen steht eine dokumentarische Ebene gegenüber, die zwischen die einzelnen Episoden der Erzählung montiert ist. Die hier abgedruckten Dokumente erfassen in polyperspektivischer Weise die Zeit nach 1968 und sind jeweils mit La versión de los otros überschrieben. Ihre Ordnung erhalten sie durch eine schlagwortartige Betitelung, welche alphabetisch von $A$ de Accidente bis $\tilde{N}$ de $\tilde{N} e-$ ros ( $y$ Ñeras) reicht. Diese von den Freunden Néstors verfassten Stellungnahmen suchen eine Antwort auf dessen brieflich gestellte Frage: »Cuéntame lo nuestro, ¿qué fue lo nuestro?« (HC, 79), indem sie die Ereignisse und die Stimmung nach dem gescheiterten Aufstand aus der subjektiven Sicht der Schreiber reflektieren. Die Kombinatorik dieser Dokumente entwickelt einen polyphonen Diskurs über das Scheitern, der die verbreitete Hoffnungslosigkeit, das Gefühl der Absurdität des Daseins sowie die ohnmächtige Wut über den Sieg des staatlichen Machtapparates wiedergibt. Die auf 
dieser Romanebene gesammelten Zeugnisse besitzen einen ambivalenten Status zwischen Fakt und Fiktion, da ihre Urheber zum Teil reale Personen sind und sie teilweise eine authentische Qualität besitzen.

So eröffnet niemand geringeres als Taibo selbst den Reigen der Verfasser. Als journalistischer Kollege und Mitglied des ehemals existierenden oppositionellen studentischen Freundeskreises, zu dem auch Néstor zählte, informiert er diesen in einem Brief über den Mordversuch des mataputas. Offensichtlich möchte Néstor seine individuelle wie auch die kollektive Vergangenheit aus dem Blickwinkel der anderen rekonstruieren, beziehungsweise die eigene Sicht der Ereignisse durch den Blick der anderen ergänzen. Neben den fiktiven Dokumenten wird aber auch ein auf den 11.1.1970 datierter Brief José Revueltas' an Arthur Miller, den Präsidenten des internationalen PEN-Clubs, über den Hungerstreik politischer Gefangener in der Cárcel Preventiva de Lecumberri zitiert. Es folgt eine Reportage Taibos über die Selbstverbrennung eines oppositionellen Arbeiters, der ein Fanal gegen die Ausbeutung setzen wollte, sowie weitere Fundstücke aus mexikanischen Zeitungen. Letztere lassen erkennen, wie 1969 die Banalität des Alltags die Ereignisse von 1968 verdrängte - eine Entwicklung, die von den staatlich gelenkten Medien gezielt gefördert wurde. Weiterhin begegnet der Leser den Briefen Unbekannter, welche die Fragmentierung der studentischen Linken schildern oder die Versuche, sich in hastigen Liebesbeziehungen über das politische Versagen hinwegzutrösten.

Einen sehr autorenbezogenen Charakter besitzt jener Brief Taibos an Néstor, in dem er mit einer »endiablada tristeza « auf 1968 zurückblickt. Der Schriftsteller steht noch unbeirrt zu seinen damaligen Idealen, auch wenn er einräumt, dass »el recuerdo del 68 visto en el 69 está reputado ultramistificado en el $70 \ll(\mathrm{HC}, 106)$. In einer Geste nostalgischer Verzweiflung fordert er den Freund auf:

Oye, pinche Néstor. ¿Por qué no vuelves y probamos a salir a la calle de nuevo? Con una pancartota que diga: Muera el mal gobierno. Tú y yo solos. Y otros cuates, si encontramos por ahí alguno. Lo hacemos y nos quitamos de encima tanta mierda, tanta nostalgia, tanta culpa de haber quedado vivos y libres, tanta culpa de haber sido derrotados. (HC, 106-107)

Dieses Aufbäumen gegen den Verlust der Vergangenheit klingt jedoch mit dem a priori zum Scheitern verurteilten Wunsch aus, die Enttäuschung durch einen Rückzug ins Private zu kompensieren: 
[...] voy a salir a la calle, a ver si encuentro alguna compañera que quiera venir a beber vermouth a mi casa, y acostarse luego conmigo. Ojalá encuentre una de las buenas, de esas que no se espantan si se despiertan a media noche y te encuentran lloriqueando abrazado a la almohada. (HC, 107)

Die Thematisierung der politischen und existentiellen Niederlage geht mit der Schilderung der Unfähigkeit einher, einen Roman herkömmlichen Musters über das Lebensgefühl von 1969 zu verfassen. Deshalb schickt der im Werk auftretende Taibo seinem Freund Néstor nicht weniger als acht incipits zu einem Roman mit dem aussagekräftigen Titel Señales en el viento zu. Doch jeder Romananfang verrinnt nach wenigen Sätzen. Indem Héroes convocados die Thematik der unvollendeten Señales en el viento aufgreift, sie aber unkonventionell gestaltet, erweist sich der Roman als atmosphärisch dicht gestaltetes und sehr realitätsnah angelegtes literarisches Experiment, welches der Phantasie und Kombinationsgabe des Lesers großen Spielraum lässt. Taibos polyphones Werk überschreitet die Gattungsgrenzen; es pflegt in pastichierender Weise den spielerisch-ironischen Umgang mit Intertexten aus der Abenteuerliteratur, der novela testimonial, dem Briefroman, der Reportage, der Literatur der Onda, aber auch dem Film und natürlich der Kriminalliteratur. Zur Erfassung der von Taibo realisierten Mexikanisierung des Kriminalromans bietet sich die Vertiefung der beiden letztgenannten Aspekte an.

Mittels seiner strukturellen Verrätselung durch Unbestimmtheitsstellen und den Einbezug von Intertexten aus dem Feld der Kriminalfiktion übt Héroes convocados auf einen detektivisch agierenden Leser eine Appellwirkung aus. Diese Anlage schafft definitiv die Verbindung zum Kriminalroman. So ist es sicherlich kein Zufall, dass sich Néstor am Ende des Romans für einige Zeit ausgerechnet nach Casablanca zurückzieht. Casablanca lautet der Titel des 1942 realisierten Kriminalfilms mit Humphrey Bogart, der ein Jahr zuvor in dem Thriller The Maltese Falcon die Hauptrolle gespielt hatte. Der Stoff zu diesem Film wiederum wurde dem bekanntesten Kriminalroman von Dashiell Hammett entnommen. Hammett gilt mit Raymond Chandler, dessen Roman The Big Sleep 1946 ebenfalls mit Bogart verfilmt wurde, als der Gründer der hard-boiled school des Kriminalromans. Hammetts und Chandlers Werke besitzen für Taibo erklärter- 
maßen eine Vorbildfunktion. ${ }^{33}$ Das Ende von Héroes convocados führt somit wieder in die Welt des Kriminalromans zurück, der das frühere Schaffen des Autors bestimmte und auch in den folgenden Jahren im Mittelpunkt seines Interesses stehen wird. Trotz seiner Eigenschaft als literarischer Exkurs bleibt Héroes convocados eng in den Kontext der Kriminalfiktion Taibos eingebettet, zu der das Werk zahlreiche Bezüge aufweist.

Die Schlusswendung des Buches besitzt auch eine poetologische Sinndimension: Zwar zieht sich Néstor aus der mexikanischen Realität in die Welt des Kriminalromans - Casablanca - zurück, aber nur, wie er in seinem letzten Satz ausdrücklich vermerkt, »[p]ara volver algún día « (HC, 121). Der Ausflug in die Welt der Fiktion, so könnte man diese Aussage unter Einbeziehung der bisherigen Beobachtungen ausdeuten, dient dem Ziel, mit neuen Erfahrungen und Einsichten in die mexikanische Realität zurückzukehren und zu ihrer Veränderung beizutragen. Diese Auslegung des Romanendes wird durch den Verweis auf die antike Mythologie bestätigt, der sich in der Namenswahl der Hauptfigur artikuliert. Im Altertum nahm Nestor trotz seines fortgeschrittenen Alters am Trojanischen Krieg teil. Zwar konnte er keine Heldentaten mehr verrichten, aber er nützte durch seinen Rat den Griechen im Kampf und unterhielt sie mit Berichten aus seiner Jugendzeit. Auch Taibos Néstor, der in Héroes convocados aufgrund seiner Erfahrungen nach 1968 als ebenso phantasievoller wie abgeklärter Erzähler auftritt, möchte dazu beitragen, dass seine Partei aus einer mexikanischen Neuauflage des Trojanischen Krieges siegreich hervorgehen kann.

Der Name der Hauptfigur erlaubt aber auch den Rückschluss auf den Kriminalroman, denn er spielt auf Nestor Burma, eine Figur des französischen Kriminalautors Léo Malet, an. Da der zeitweise dem Surrealismus nahestehende Vater des französischen roman noir linksoppositionelle Überzeugungen vertrat, liegen die Affinitäten zu Taibos politischer Haltung und dem surrealen Erzählstrang seines Romans auf der Hand. Doch die Analogien reichen weiter: Malet wollte das Paradigma des US-amerikani-

33 Weitere Referenzautoren sind nach Taibos Bekunden: Manuel Vázquez Montalbán, Jerome Charyn, Jean P. Manchette, Jean F. Vilar, Juan C. Martelli, Alberto Sperati, Per Wahloo, Robert Littell, Martin Cruz Smith, Rodolfo Walsh, Miguel Bonasso, Joseph Wambaugh und Guillermo Thorndyke. Von den mexikanischen Kriminalautoren hält Taibo lediglich Rafael Bernal für lesenswert, cf. Ilán Stavans (1994: 36). Die Parallelen zu Chester Himes' Romanen, die im Übrigen auch von Taibos Detektivfigur Belascoarán Shayne gelesen werden, erschließt Persephone Braham (1997). 
schen Krimis nicht einfach imitieren, sondern seinen Kriminalromanen ein ausgesprochen französisches Gepräge verleihen. In diesem Sinne lassen sich seine tableauartigen Schilderungen von Paris und Montpellier oder der Gebrauch des français populaire und des argot deuten. ${ }^{34}$ Taibo mexikanisiert seine Werke, indem er der Stadtlandschaft der mexikanischen Metropole eine große Bedeutung einräumt; ferner erweist sich die Diktion seiner Figuren nicht minder realistisch als in den Werken des Franzosen. Verfolgt man diese Spur, tun sich weitere Bezüge zwischen Malet und Taibo auf, denn wie Malet liebt es Taibo, sich hinter seinen Personen zu verstecken. So schuf Malet die Figur des investigativ tätigen Journalisten Johnny Metal, einem Anagramm des Autorennamens. Sein Detektiv Nestor Burma wiederum nimmt in Abattoir ensoleillé mittels des Anagramms Burton Rames die Identität eines Journalisten an. Beide Journalistenfiguren sind das Produkt einer Verschlüsselung der faktischen beziehungsweise fiktiven Realität. Ähnlich gestaltet sich das Verhältnis zwischen dem studentischen Aktivisten und Journalisten Néstor und Taibo, denn Néstor verweist in vielfältiger Weise auf Taibos politische Überzeugungen, seine Weltsicht und nicht zuletzt auf seine journalistische Tätigkeit. Wie in Héroes convocados weisen auch die Hauptfiguren der übrigen Kriminalromane Taibos eine große personale und ideologische Nähe zu ihrem Autor auf. Realität und Fiktion stehen in einer äußerst engen Wechselbeziehung. ${ }^{35}$ Vor allem durch die strukturelle Verrätselung, das Verwischen der Identitäten und intertextuelle Anspielungen schafft Taibo mit Héroes convocados ein Werk, das bei der Gattung des Kriminalromans erhebliche Anleihen macht.

Es ist symptomatisch für die Darstellung der Lebenssituation der Generación del 68, dass wir unter den Héroes convocados keinem Mexikaner begegnen. Erst die Internationalisierung der kulturellen Szene nach 1968 und der Dialog mit außermexikanischen Literaturen, so eine Botschaft des Romans, beendete das phantasielose Vakuum der mexikanischen Öffentlichkeit. Taibo trägt in seinen Kriminalromanen zur Kompensation dieses

34 Cf. Jean-Paul Schweighaeuser (1984: 31ss.).

35 In dem Kriminalroman La vida misma beispielsweise wird ein Kriminalautor von den Vertretern des kommunistisch regierten und deswegen von den staatlichen Autoritäten sabotierten Santa Ana gebeten, als Polizeichef zu arbeiten, nachdem seine beiden Amtsvorgänger ermordet wurden. Der neue Polizeichef klärt die Ermordung einer Nordamerikanerin auf, welche auf Geheiß konservativer Politiker, die in eine Betrugsaffäre verstrickt waren, getötet wurde. Romantechnisch ist La vida misma insofern in der Nähe von Héroes convocados angesiedelt, als die auktoriale Präsentation des Haupterzählstrangs regelmäßig durch Briefe Fierros an seine Frau sowie durch dessen Notas para la historia del ayuntamiento rojo de Santa Ana unterbrochen wird. 
Defizits bei, indem er den mexikanischen Detektiv zu einem von internationalen Paradigmen inspirierten, (post-)modernen Helden stilisiert. Der etwas kauzige, aber sympathische Einzelgänger tritt in Taibos Kriminalromanen mit den Idealen von 1968 gegen die staatlich geförderte Korruption und das Verbrechen an. ${ }^{36}$ Taibo stellt sich aufgrund seiner im Roman verarbeiteten Sozialkritik in die Tradition der hard-boiled novel und des roman noir, reichert aber deren Darstellung der negativen Seiten der Gesellschaft mit einer politischen Botschaft an. Die Kritik an den mexikanischen Verhältnissen erhält bei Taibo letztlich den gleichen Stellenwert wie die Lösung des Kriminalfalles. Dies wird dadurch ermöglicht, dass das in gattungsgeschichtlicher Hinsicht ohnehin periphere Genre des Kriminalromans in seiner von Taibo geschaffenen Form als nueva novela policiaca eine markante oppositionelle Funktion erhält. Die Mexikanisierung des Kriminalromans dient in diesem Sinne als Kritik an der mexikanischen Realität.

In exemplarischer Weise soll eine Analyse von Algunas nubes ${ }^{37}$ die gesellschaftskritischen und ästhetischen Positionen, die Taibo in seinen Kriminalromanen vertritt, erschließen. Das Werk bildet den vierten Roman einer Serie um den Detektiv Héctor Belascoarán Shayne, die 1976 mit Días de combate einsetzte. Algunas nubes ist neben Cosa fácil ${ }^{38}$ der bislang wohl größte literarische Erfolg Taibos: Zwei Neuausgaben erschienen 1986 sowie 1988, und in fast allen darauffolgenden Jahren wurde je eine weitere Auflage gedruckt. Der Roman schildert, wie Héctor den Mord an dem Ehemann einer Bekannten seiner Schwester aufklärt, der nach dem Ableben seines Vaters Costa ein überraschend großes Vermögen geerbt hatte. Da finstere Gestalten das Leben Anitas, so der Name der jungen Witwe, bedrohen und sie zum Verzicht auf ihr Erbe zwingen möchten, ist Eile geboten. Die Ermittlungen führen den Detektiv zunächst zu einer zwielichtigen Figur, die er während seines Studiums unter dem Namen La Rata kennengelernt hatte und die im Umfeld von 1968 als Streikbrecher und Spitzel wirkte. Als Anwalt steht La Rata nun in engem Kontakt mit dem korrupten und verbrecherischen Polizeiapparat. Über diese Spur erfährt Héctor, dass ein hochrangiger Polizeivertreter in den Mord verwickelt ist. Es stellt sich

36 Hierin bestehe die größte Herausforderung an den zeitgenössischen mexikanischen Kriminalroman. Siehe Paco Ignacio Taibo II (1986: 41).

37 Mexiko: Mortiz, 1994 ('1985). Verweise auf diese Textausgabe werden im Weiteren durch Angabe der Sigle AN im fortlaufenden Text vorgenommen.

38 Mexiko: Planeta, 1998 ('1977). 
ferner heraus, dass dieser Polizist ein Verwandter des verstorbenen Costa war. Costa hatte für ihn Schwarzgeld aus Banküberfällen verwaltet und gewaschen. Als Bankräuber betätigten sich ehemalige Polizeiangehörige, deren Aktionen Costas Verwandter gegen einen entsprechenden Anteil deckte. Nach der Aufklärung des Falles vermag Héctor den hochrangigen Polizisten jedoch nicht dingfest zu machen, da dieser vor der Öffentlichkeit zunächst noch sein Gesicht wahren kann. Als aber dessen skandalöses Doppelspiel aufzufliegen droht, liquidiert ihn das System durch einen gestellten Unfall. Anita stiftet das ererbte Geld schließlich einer Gesellschaft für Krebsforschung. Die letzten Sätze des Romans thematisieren ein Leitmotiv, das auch für andere Werke Taibos nachweisbar ist: den Regen in MexikoStadt, der aber auch im übertragenen Sinn die Stadt nie vom Verbrechen reinwaschen kann. "Mira qué nubes, va a llover en grande«, meint die Schwester des Detektivs. »Han de ser nubes de mierda - dijo Héctor sin alzar la vista« (AN, 125).

So weit in kurzen Zügen der Inhalt des Romans, dessen Analyse in zwei Schritten erfolgt: Zunächst möchte ich Taibos Mexikanisierung des Kriminalromans mittels seiner Darstellung der Detektivfigur und des Milieus erschließen, um sodann die Analyse intertextueller Anspielungstechniken in den Mittelpunkt der Betrachtung zu stellen. Sie schafft wiederum die Grundlage für die Erörterung der für Taibo typischen Verzahnung von mexikanischer Realität und Romanfiktion.

Héctor Belascoarán Shayne: Der sperrige Name des Detektivs, der aufgrund seiner Physis und seines Weltbildes als alter ego Taibos erscheint, lässt aufhorchen. Der Vorname erweist sich als Reminiszenz an den mutigen Beschützer Trojas in Homers Ilias. Héctors Vater war ein politisch linksorientierter baskischer Seemann, und seine Mutter, so erfährt der Leser des ersten Kriminalromans Taibos, Dias de combate, eine irische Sängerin. Hinter Shayne verbirgt sich auch ein Fingerzeig auf eine Figur des nordamerikanischen Kriminalschriftstellers Brett Halliday, namens Michael Shayne. Halliday gestaltete seinen Protagonisten nach der Person eines mexikanischen Seemanns, den er einmal auf einem Öltanker kennengelernt hatte. ${ }^{39}$ In Héctors Namen verbinden sich somit Anspielungen auf Spanien,

39 Ilán Stavans (1993: 134). 
die zweite Heimat Taibos ${ }^{40}$, mit einer Referenz an die hard-boiled school. Schließlich erinnert der Name des Detektivs in kompositorischer Hinsicht an das Pseudonym B. Suárez Lynch, mit dem Borges und Bioy Casares 1946 die gemeinsam verfasste Kriminalerzählung Un modelo para la muerte publizierten. Héctors Name erweist sich daher als das hybride Produkt einer kultur- und epochenübergreifenden Kombinatorik.

Doch nicht genug der Bezüge zur internationalen Kriminalliteratur: Wie im Falle Sherlock Holmes', in dessen Bleibe in der Londoner Baker Street sich mittlerweile ein Holmes-Museum befindet, kennen wir die Adresse Belascoaráns in der Calle Artículo 123 im Zentrum Mexikos. Wie symbolträchtig diese Wahl ist, belegt der Blick auf den Stadtplan: Héctor hat sich in einer Nebenstraße des Palacio de Bellas Artes, also abseits der offizialisierten Schönen Künste niedergelassen. Sein Büro ist aber auch nur vier Metrostationen von der Plaza de las Tres Culturas entfernt, die 1968 traurige Berühmtheit erlangte. Hinzu kommt der in Héroes convocados nachzulesende Vermerk, die Revolte von 1968 habe 123 Tage gedauert (HC, 127-128). Ein Blick in die mexikanische Verfassung offenbart schließlich, dass der Artikel $123 »$ del trabajo y de la previsión social ${ }^{41}$ handelt. Regelungen wie der Acht-Stunden-Tag, das Verbot von Kinderarbeit, gleicher Lohn für gleiche Arbeit, Versicherungspflicht, Demonstrations- und Streikrecht sind hier festgeschrieben, doch zwischen Verfassungstext und Verfassungswirklichkeit klaffen Welten. Belascoarán Shaynes Adresse verschlüsselt somit biographische, poetologische und politische Aussagedimensionen.

Taibo wählte nach eigenem Bekunden die hard-boiled novels Hammetts und Chandlers als Grundlagen seines Schaffens. Entsprechend präsentiert sich Héctor als mexikanisiertes Pendant zu Chandlers Detektiv Philip Marlowe. Wie Marlowe hat auch Taibos Protagonist erfolgreich studiert, bevor er den Entschluss fasste, als Privatdetektiv zu arbeiten. Zugleich unterläuft Taibo das im nordamerikanischen Romanmodell herrschende Klischee des abgebrühten Ermittlers: Héctor, dessen Schießkünste

40 In seiner Geburtsstadt Gijón organisiert Taibo für die International Crime Writer Association seit 1988 alljährlich eine Mischung aus Volksfest und Buchmesse zum Kriminalroman. Nähere Informationen unter http://spin.com.mx/ mschwarz/snes.html.

41 Constitución Politica de los Estados Unidos Mexicanos. Constitution Politique des États Unis du Mexique. Political Constitution of the Mexican United States, Mexiko: Cámara de Senadores 1962, p. 63 . 
sich in Grenzen halten, ist kein Supermann. Dafür besitzt der detective demócrata (AN, 85) eine sozialromantische, idealistische Ader. Héctor verkörpert in Taibos Romanen eine positive, individualisierte Handlungsethik abseits der gesellschaftlichen Norm. Damit steht er gerade zu Hammetts Ermittler im Gegensatz, der oft dieselben zweifelhaften Grundsätze wie die von ihm gejagten Verbrecher vertritt.

Héctor ist nicht zum Detektiv geboren, denn er gab als Quereinsteiger nach einer Sinnkrise seine finanziell wohldotierte Tätigkeit als Ingenieur bei General Electric auf und verließ seine Frau, um sich als Detektiv durchs Leben zu schlagen. Mit einem Fingerzeig auf die Tradition des Genres und den referenziellen Charakter seiner Figur lässt Taibo Héctor sein neues Handwerk durch einen Fernkurs, also mittels der Literatur, erlernen. Zur Aufbesserung seines prekären Lebensunterhaltes tritt der Detektiv in Dias de combate sogar in einem Fernsehquiz als Spezialist für die berühmtesten Meuchelmorde der Geschichte auf.

Belascoarán Shayne ist wahrlich keine Heldenfigur, und er ist auch nicht unsterblich. So parodiert Taibo den Mythos des klassischen Ermittlers, indem er seinen Detektiv in No habrá final feliz ${ }^{42}$ einem Mordanschlag zum Opfer fallen lässt. In seinem nächsten Roman, Regreso a la misma ciudad y bajo la lluvia ${ }^{43}$, erweckt er ihn jedoch wieder zum Leben. Aber selbst dieses Spiel mit der Norm verbirgt ein literarisches Zitat, denn bereits Arthur Conan Doyle ließ 1894 Sherlock Holmes in The Memoirs of Sherlock Holmes sterben, um sich von seiner Figur zu befreien. Aufgrund heftiger Leserproteste musste er ihn aber wiederauferstehen lassen. Taibo ging es - so seine Auskunft - nicht anders als dem Briten. ${ }^{44}$

Héctor weiß sehr wohl, dass er lediglich im Einzelfall und an der Oberfläche des mexikanischen Systems für Recht und Ordnung sorgen kann. Diese Erfahrung bringt es mit sich, dass er über eine gehörige Portion Sarkasmus und Selbstironie verfügt. ${ }^{45}$ In Algunas nubes heißt es hierzu:

42 Mexiko: Planeta, $1985\left({ }^{\prime} 1981\right)$.

43 Mexiko: Planeta, 1989.

44 'I didn't kill him, dramatic logic killed him, the progression of facts. Then the readers protested. I decided that the saga wasn't finished and revived it. White magic!«, in: Ilán Stavans (1994: 35). Cf. auch die von Stavans zitierten Ausführungen Taibos in der Nota del autor von Regreso a la misma ciudad y bajo la lluvia (1993: 142-143).

45 Cf. Héctors Aussage: „Ser detective en México era una broma [...]. Quizá lo único que el país no le perdona era que se tomara su propia broma en serio«, in: Taibo, Cosa fácil, p. 18. 
Sabía que cuando llegara al final, si llegaba, se iba a encontrar con una pared que impediría la justicia. (AN, 50)

Taibos Protagonist steht in typologischer Hinsicht somit zwischen der traditionellen, erfolgreichen Detektivfigur und ihrer postmodernen, vom Scheitern markierten Ausformung. ${ }^{46}$ Seine mexikanistische Prägung schafft eine Alternative zum traditionellen Kriminalroman, in dem das Verbrechen als eine ausnahmehafte Störung der gesellschaftlichen Ordnung erscheint, die der Detektiv wiederherstellt. In Taibos Romanen klärt der Detektiv zwar den Kriminalfall auf, doch obsiegt letztlich das verbrecherische mexikanische System. ${ }^{47}$ Das fiktionale Spiel mit gesellschaftlichen und politischen Fakten bietet dem Autor dabei einen geeigneten Freiraum zur Artikulation und Popularisierung seiner Kritik an der politisch motivierten Konstruktion einer mythischen mexikanischen Realität.

In Algunas nubes äußert sich der durch die Erfahrung von 1968 initiierte systemkritische Impetus des Schaffens Taibos besonders deutlich im Zusammenhang mit der Figur La Rata, deren Karriere ausführlich geschildert wird (AN, 39ss.). Während der Studentenrevolte profilierte sich La Rata zum führenden »gángster estudiantil« $(\mathrm{AN}, 41)$, der als staatlich geförderter Agent die studentische Bewegung unterwanderte. Dank seiner antikommunistischen Aktivitäten in der universitären Unterwelt knüpfte er rasch Kontakte zum politischen System,

aquella fuente de poder [...] en la que se materializaba el estado mexicano: un funcionario en el Departamento del D.F., la Dirección General de Preparatorias de la UNAM, un secretario de la facultad de Derecho, un dirigente prísta de las colonias del sur del D.F., un comandante de grupo de la judicial, en fin, el Estado Mexicano. (AN, 42)

Wo sich die Staatsmacht nicht die Hände schmutzig machen wollte, stand La Rata bereit, Wahlen zu stören, Angst zu verbreiten, Streiks zu brechen, einen Professor zu entführen oder Informationen an die Polizei zu verkau-

46 Zu dem Scheitern des Detektivs cf. Ulrich Schulz-Buschhaus (1997: 334-335).

47 Die Kriminalautorin María Elvira Bermúdez umschreibt das spezifische Rechtsempfinden der Mexikaner in Abgrenzung von jenem der angelsächsischen Länder, in denen der Respekt vor dem Gesetz ausgeprägter sei: "El latino, el hispanoamericano y sobre todo, el mexicano, se distinguen en cambio por un escepticismo sin recato hacia el poder de la justicia abstracta y por un desdén amargo hacia la actuación de los depositarios de la justicia concreta. Para el mexicano, revancha es sinónimo de justicia; y la revancha sólo de sí mismo puede dimanar y convertirse en acto«, zitiert nach Duncan (1991: 212). In Dias de combate lässt Taibo den Mörder vermerken, die Regierung bringe an einem Tag mehr Menschen um, als er dies in einem ganzen Leben tun könnte (1976: 160 und 222). 
fen. Nach 1968 baute er mit Duldung der Polizeibehörde eine Stadtguerrilla auf, welche von Bankraub lebte und für Männer in öffentlichen Schlüsselpositionen die groben Arbeiten verrichtete. Wie sehr diese in der Fiktion am Beispiel von La Rata geschilderte Vermischung von Verbrechen und staatlicher Autorität der Realität entspricht, stützt Taibo in Algunas nubes durch den Hinweis auf eine Erhebung der Nachrichtenagentur ANSA, nach welcher die Spuren von $76 \%$ aller Kapitalverbrechen in der Hauptstadt zur Polizei hinführen $(\mathrm{AN}, 80){ }^{48}$

Die Problematisierung des offizialisierten Mexikobildes geht mit einer für die nueva novela policiaca typischen Darstellung von Mexiko-Stadt einher. Wie Hammett, Chandler und die Autoren des roman noir situiert Taibo seine Romane im großstädtischen, mafiös organisierten Verbrechermilieu, dem er durch einen authentischen Jargon große Lebendigkeit vermittelt. Taibos Detektiv muss dabei in einem höchst irrationalen, chaotischen und kafkaesk gestalteten Umfeld ermitteln, wie es nur el monstruo, die Hauptstadt, bietet. ${ }^{49} \mathrm{Zu}$ den Irrationalismen der Romane Taibos zählt in diesem Zusammenhang, dass Héctor wie viele seiner Zeitgenossen el D.F. zugleich hasst und liebt. ${ }^{50}$ Ähnlich wie Héctor erging es schon Chandlers Detektiv Marlowe im Hinblick auf L.A. Die Bedeutung der Aufklärung eines Falles, wie sie im pointierten Rätselroman nach dem Muster des whodunit im Mittelpunkt stand, wird abgelöst durch »una novela cuyo eje central es la atmósfera $\aleph^{51}$. Taibo möchte die alten Strukturen der Gattung erneuern und »a truly national, popular, and populist literature rooted in the reality of my own city, a literature that would be able to find its own readers $\ll^{52}$ schaffen.

48 "Criminality forms part of the system and is incorporated into it in a logical and coherent manner. [...] I live in a city where the police produce more deaths than all of the underworld organizations, the Mafia, and any number of marginal lunatics. Luis González de Alba, a student leader of the Tlatelolco movement of 1968, was absurdly imprisoned for four years for setting fire to a streetcar in the intersection of two streets, a place where there had never been rails, and at a time during which he was giving a lecture before thousands of witnesses on the other side of the city. To him, of course, we owe the famous phrase: ) The police is always to be blamed «, Taibo im Interview mit Ilán Stavans (1994: 37).

49 Taibo räumt ein, dass sein Stadtbild im Roman nicht nur von Hammett und Chandler, sondern besonders nachhaltig von John Dos Passos geprägt wurde. Siehe Juan Domingo Argüelles (1990: 14).

50 Cf.: »Tomarse a broma, tomar en serio la ciudad, ese puercoespín lleno de púas y suaves pliegues. Carajo, estaba enamorado del D.F. Otro amor imposible a la lista. Una ciudad para querer, para querer locamente. En arrebatos«, in: Taibo, No habrá final feliz, p. 22. Cf. ferner: »La ciudad es las ciudades. Es un espacio múltiple, no único. Es rica, diversa, no te acabas, como bien dice la raza. La diversidad misma es un valor «, in: Pablo María Molinet (1997).

51 Juan C. Ramírez / Verónica Rodríguez Sifontes (1992: 43).

52 Paco Ignacio Taibo II (1991: 9). 
Mit der Politisierung seiner Kriminalromane und dem gesellschaftskritischen Ansatz seines Detektivs möchte sich Taibo von der Tradition des Genres distanzieren. Nach eigenem Bekunden besitzen daher für ihn die mexikanischen Kriminalautoren María Elvira Bermúdez, Antonio Helú, Pepe Martínez de la Vega sowie Rafael Solana als parodists und imitators keine Vorbildfunktion. ${ }^{53}$ Der pauschale Vorwurf, die genannten Autoren hätten völlig unpolitische Romane verfasst, hält jedoch einer Überprüfung nicht stand. Zwar ist Taibo der erste mexikanische Kriminalautor, der die Politisierung des Genres systematisch verfolgt, aber zumindest ansatzweise lassen sich bei seinen Vorläufern gesellschaftskritische Stellungnahmen nachweisen. So thematisiert beispielsweise Martínez de la Vega die in Mexiko nicht unübliche Praxis des Wahlbetrugs. ${ }^{54}$

Gerade in der Evokation einer Atmosphäre, in der die soziale Problematik, das Verbrechen und die politische Korruption zu einem belastenden Alltag werden, sieht Taibo das besondere Anliegen des género neopoliciaco. Er stilisiert seinen Detektiv als sympathischen Einzelgänger und $>\mathrm{Ge}$ fühlssozialisten<, der mit den Idealen von 1968 gegen das Verbrechen antritt. Die von ihm ins Leben gerufene nueva novela policiaca besitzt eine markant oppositionelle Funktion. Taibos Erfolge gerade in Kuba, wo zeitweise kein ausländischer Autor mehr Bücher verkaufte als der Mexikaner, bestätigen die von sozialistisch-marxistischen Überzeugungen getragenen Tendenzen seiner Werke.

Das von Taibo in seinen Romanen häufig realisierte Verfahren der literarischen Transkulturation lässt sich in Algunas nubes mittels der im Kontext der postmodernen Ästhetik zu situierenden textuellen Anspielungen erschließen. Damit zusammenhängend bietet sich auch die Kommentierung der von Taibo durchgeführten Mischung von Fakt und Fiktion an. An den letztgenannten Aspekt soll zunächst angeknüpft werden. In Algunas nubes hört Héctor nach der Unterredung mit La Rata, wie dieser seinen Männern den Auftrag erteilt, einen in der Colonia Condesa lebenden novelista pendejo (AN, 64) für einige Tage durch einen fingierten Unfall aus dem Weg

53 Ilán Stavans (1994: 36). Die genannten Autoren stehen nach Taibo für mjusto lo contrario de lo que realmente queríamos hacer: aquello era la copia burda, mal calcada y mal escrita de la novela policíaca menos importante«, in: Juan Domingo Argüelles (1990: 14).

54 Weitere Beispiele für kritische Tendenzen des mexikanischen Kriminalromans benennt Amelia S. Simpson (1990: 87ss.). Die Verfasserin neigt jedoch dazu, die bei Taibo im Vergleich zu anderen Autoren besonders pointierte und als Leitmotiv in Erscheinung tretende Systemkritik unterzubewerten, ibid., p. 96. 
zu schaffen. Héctor ermittelt, dass dort niemand geringeres als der Lyriker José Emilio Pacheco und der Kriminalschriftsteller Paco Ignacio Taibo II wohnen. Der Detektiv begibt sich sofort zu Taibo, um ihn zu warnen.

In überraschender Weise überschreitet Algunas nubes durch den Kontakt zwischen fiktiver Person und Autor die in den übrigen Werken Taibos zwar durchlässige, aber immer noch textuell markierte Grenze zwischen Kunst und Leben. ${ }^{55}$ Taibos Kriminalroman erhält zugleich den Charakter eines Palimpsestes, da er auf Werke anspielt, welche die Frage nach Sein und Schein ansprechen. Als die drei zentralen Referenzautoren Taibos fungieren hierbei der von ihm verehrte Cervantes sowie Unamuno und Pirandello.

Der Verweis auf Cervantes' Don Quijote, dessen zweiten Teil Taibo nach eigenem Bekunden besonders schätzt, bietet sich in mehrfacher Hinsicht an: Das offenkundigste Indiz besteht darin, dass in Algunas nubes der hinter sämtlichen Morden stehende Polizeikommandant den Namen Saavedra trägt. Wie der spanische Autor pflegt auch Taibo einen spielerisch-parodistischen Umgang mit seinen Hypotexten. Kann Don Quijote als Kritik der Ritterromane gelesen werden, so wendet sich Taibo vom lediglich unterhaltsamen, wirklichkeitsfremden und strukturell iterativen konventionellen Kriminalroman ab. Ferner spielt Taibo wie Cervantes auf die fließenden Übergänge zwischen Fakt und Fiktion an. Bekanntlich fungiert im zweiten Teil des Romans Don Quijote als Kommentator jenes Buches, das seine Taten schildert (insbesondere II, 2-4) ${ }^{56}$ Die literarische Figur tritt nicht mehr als Erfindung ihres Autors auf, sondern als leibhaftig existierende Person, die über ihre Funktion in der Literatur reflektiert. Parallelen zu Unamunos Roman Niebla sowie den in Maschere Nude gesammelten Theaterwerken Pirandellos liegen in diesem Zusammenhang ebenfalls auf der Hand. Doch auch Georges Simenon muss genannt werden, der in Les mémoires de Maigret den Kommissar in einem autobiographischen Rückblick berichten lässt, wie der noch junge Simenon ihn nach ihrer ersten Begeg-

55 Entsprechend leitet ein Epigraph Nazim Hikmets das hier angesprochene Kapitel ein: "Yo creía que la gente sólo pensaba en esas cosas en las novelas « (AN, 67).

56 Cf. Christoph Strosetzki (1991: 132-133). »I would need much more space to tell how I reread the Quijote in Barcelona, beginning with the second part, which deals with imagination and modernity, and ending with the first part $«$, in: Paco Ignacio Taibo II (1991: 6). 
nung im Polizeirevier gegen sein Einverständnis zu einer Romanfigur machte. ${ }^{57}$

In Don Quijote erhält der Protagonist eine eigene, scheinbar entfiktionalisierte Wirklichkeit. Im Gegenzug fiktionalisiert sich Cervantes durch die Erzählung des Cautivo als Person seines eigenen Romans. In Algunas nubes führt Taibo dieses Muster weiter, indem er sich direkt, ausführlich und realitätsnah als vollschlanken, kettenrauchenden Colasüchtigen einbringt. In Anlehnung an Cervantes fiktionalisiert sich Taibo somit als Person der Realität, während er Héctor wie zuvor Cervantes seinen Don Quijote als Person der Fiktion materialisiert. ${ }^{58}$ Entsprechend meint Taibo zu Héctor: »Tú no escribes, ¿verdad? No, tú eres del estilo protagonista, no del estilo autor $[\ldots] \lll(\mathrm{AN}, 68)$. Wir begegnen dem Paradox, dass die konventionelle Trennung zwischen Realität und Fiktion ebenso wie die gängige Rollenverteilung zwischen Figur und Autor zwar semantisch behauptet, situativ jedoch aufgehoben wird. So ist es nicht überraschend, dass sich Héctor und Paco, deren Alter auch nur um einen Monat differiert, hervorragend verstehen.

Der durch die Überschreitung von Fakt und Fiktion insinuierte Fingerzeig auf Pirandellos in Maschere nude gesammelte Dramen erlaubt es, unter Rekurs auf das bei dem Italiener zentrale Maskenmotiv von der Maskiertheit des Daseins in der mexikanischen Gesellschaft zu sprechen. Hiermit wiederum erschließt sich ein impliziter Verweis auf Octavio Paz' El laberinto de la soledad, der in dem Kapitel »Máscaras mexicanas« die Mexikaner als »simuladores « bezeichnet. ${ }^{59}$ Doch Taibo nuanciert die Interpretationen des Maskenmotivs durch Pirandello und Paz: Bei Pirandello führt selbst das Lüften der Maske nicht zur Wahrheit, da die Alternative von gut und böse nicht mehr besteht und gesellschaftliche Urteilskategorien ambivalent geworden sind. ${ }^{60}$ Anders gestaltet sich die Demaskierung der Lüge bei Taibo: Sein und Schein bleiben zwar in einer unaufhebbaren dialektischen Spannung, doch wird der Lüge von einer Warte der ethisch-moralischen Wahrheit her zumindest kurzfristig ihre Maske entrissen. Dieser Sieg

\footnotetext{
57 Georges Simenon (1950).

58 Da Simenon vermutlich ebenfalls auf Cervantes rekurriert, verfährt er in seinem zitierten Text ana$\log$.

59 Octavio Paz (1991 ['1950]: 33ss.).

60 Cf. Felicity Firth (1982) sowie Karl Hölz (1988).
} 
der Wahrheit bleibt aber anders als im traditionellen Kriminalroman ephemer. ${ }^{61}$

Im Unterschied zu Paz, der eine kollektive Identitätsbestimmung >des Mexikaners anstrebt und der inspiriert durch den Existentialismus und die Tiefenpsychologie zu einem pessimistischen Ergebnis gelangt, differenziert Taibo sehr wohl: Bei ihm tragen nur die Vertreter des Verbrechens und die von ihm infizierten Personen des Establishments Masken. Taibo gibt den "máscaras mexicanas«, von denen Paz spricht, eine politische, auf den kriminellen submundo der Gesellschaft gerichtete Auslegung. Die scheinbare Seriosität der Politik verhüllt aus seiner Sicht das Verbrechen. Die politischen Morde des vergangenen Jahrzehnts deuten auf die Gültigkeit dieses Befundes hin.

In Algunas nubes ist nicht nur der Detektiv, sondern auch der Schriftsteller Taibo dem Polizisten Saavedra, der in eine Reihe von Mordfällen und in den Drogenhandel verwickelt zu sein scheint, auf der Spur. Weil Héctor Taibo vor La Ratas Leuten warnt und beide gemeinsam die Verbrecher in die Flucht schlagen, wird das konventionelle Abhängigkeitsverhältnis zwischen Figur und Autor vertauscht beziehungsweise nivelliert. Die Episode endet mit einer selbstironischen Anmerkung, welche erneut die Fiktionalität als Faktizität erscheinen lässt:

- ¿Qué tal me salió? - preguntó Héctor.

- No tan bien como en las novelas, pero bastante a toda madre, yo diría. (AN, 76)

Auch im Folgenden pflegt Taibo eine humorvolle Selbstironie, wenn sich Anita mit Héctor über ihn unterhält und die Frau zu Taibos Romanen meint: »[N]o creo que gane el Nóbel, pero a mí me gusta« (AN, 83). In der Tat bildet der Publikumsgeschmack die einzige Urteilsinstanz, welche der Autor anerkennt.

In Taibos Roman nutzt der Schriftsteller das Zwiegespräch mit Héctor, um dem Konzept des género neopoliciaco entsprechend harsche Kritik an den mexikanischen Verhältnissen zu üben. Angesichts der über ihm schwebenden Morddrohung denkt er über seine Möglichkeiten nach, als Autor zu einer Veränderung beizutragen:

61 »[...] la verdad, por naturaleza en México, tiene una entropía hacia ocultarse, hay una entropía de la mentira en este país. Por lo tanto todo lo que sucede tiende a distorsionarse o a convertirse en falso, todo a enmascarse«, Taibo gegenüber Juan C. Ramírez / Verónica Rodríguez Sifontes (1992: 43). 
- Este país mata, Héctor, - le dijo el escritor mientras se sobaba el puente de la nariz por enésima vez - Mata de muchas maneras. Mata por corrupción, por aburrimiento, por ojete, por hambre, por desempleo, por fría, por bala, por madriza. No tengo inconveniente en echarme un trompo contra el sistema. Pero no así, no de Shayne al desconocido, no de western. No solito, chingá. Llevo peleando los últimos trece años. Estuve en el movimiento de 68, pasé por un partido de izquierda, me metí al sindicalismo, trabajé con obreros industriales, organicé sindicatos, hice revistas, folletos, renuncié a un montón de empleos, no me dediqué a hacer billetes, nunca trabajé para el PRI, no debo nada, o casi nada, cuando la cagué no maté a nadie; si jodí fue por irresponsable, y no por corrupto o cabrón. [...] No me quiero morir así. [...] No me quiero rendir a lo güey, Héctor, pero tampoco estoy dispuesto a echarme una guerra en solitario. ¿Quién soy yo, Jane Fonda o qué pedo? Esas guerras ni se ganan ni se pelean. El escritor estrella y su máquina de escribir contra el subjefe de la judicial y pinchemil guaruras todos con pistolas, rifles, metras, cañones, bazukas y sacamierdas. ¿Qué rollo? Si el de la tintorería de aquí abajo me dice que corrieron a su hijo de una chamba y no le quieren pagar la liquidación como es de ley, me cae que me meto a echar una mano, si puedo escribir la verdad y encuentro quien la publique, la escribo. Carajo, pero esto. (AN, 87-88)

Der Taibo des Romans vertritt ein pessimistisches Selbstbild. Da er das menschenverachtende politische System kaum alleine verändern kann, sucht er unter seinen Lesern Verbündete, damit es ihm gelingen möge, wenigstens im Alltag der Gerechtigkeit zu kleinen Siegen zu verhelfen. Deshalb - so gesteht der in Algunas nubes auftretende Schriftsteller - hat er auch das Projekt, die Affäre Saavedra in einem Roman zu verarbeiten, aufgegeben. Taibo beschreibt am Beispiel seines fiktionalisierten Ich das Problem des oppositionellen Engagements in der mexikanischen Realität. Héctors Replik scheint die Skepsis des Schriftstellers im Roman zu bestätigen:

- Mira, pinche Paco - dijo Héctor apagando su último delicado en el cenicero de latón -. No, yo detective, yo pura madre. Yo lo único que pasa es que no sé escribir novelas, entonces me meto en las de otros. Yo solito contra el sistema, ya vas. [...] Me emputa tanto como a ti, me reencabrona cómo se van consumiendo el país y lo van haciendo mierda. Soy tan mexicano como cualquiera. Ha de ser por eso que ya no creo en nada más que en supervivir y seguir chingando. [...] Yo soy detective porque me gusta la gente. $(\mathrm{AN}, 89)$

Im Unterschied zum Detektiv des traditionellen Kriminalromans glauben Autor und Figur nicht daran, die gesellschaftliche Ordnung herstellen zu können. Dieser Desillusion steht aber ihr Handeln gegenüber: Taibo verfasste seine gesellschaftskritischen Kriminalromane so rasch und regelmäBig wie kaum ein anderer Autor, und Héctor bemüht sich in ihnen mit glei- 
cher Regelmäßigkeit darum, der überstaatlichen Moral zum Recht zu verhelfen. ${ }^{62}$ Der für beide frustrierenden Tatsache, dass das mexikanische System sämtliche Versuche, gegen es anzugehen, übersteht ${ }^{63}$, begegnen sie mit einer Art trotziger Hartnäckigkeit. Camus' Sisyphos könnte als ihre Emblemfigur gelten. ${ }^{64} \mathrm{Im}$ Unterschied zu seinem literarischen alter ego hat Taibo in Algunas nubes gleichwohl die Affäre um Saavedra literarisch verarbeitet, so dass dem verhaltenen Pessimismus des Schriftstellers im Roman das verhaltene Engagement des Romanschriftstellers entgegentritt.

Auf den letzten Seiten nimmt Algunas nubes erneut eine überraschende Wendung. Ein Überfall der Gangster auf Héctor und Anita scheitert dank des im Stil der hard-boiled novels beschriebenen massiven Einsatzes zweier Freunde aus dem Ringermilieu, und der Detektiv kann jene Männer dingfest machen, die Anita bedrohen. Saavedra sieht sich daraufhin gezwungen, seine Kumpane festzunehmen, und um sein Gesicht zu wahren, muss er Héctor sogar zu dessen Erfolg gratulieren (AN, 114). Der Detektiv rechnet nun mit der Rache Saavedras, als ihn sein Bruder, der mit dem Taibo des Romans befreundet ist, anruft:

- Está muerto, hermano. Se mató o lo mataron en un accidente de coche en la carretera de Querétaro.

- ¿Quién, Saavedra?

- Sí, pero también el escritor. A los dos. Se mataron o los mataron juntos. Un choque en la carretera. [...] Iban juntos en el automóvil a más de cien y se embarraron contra un tráiler. (AN, 124)

In seinem Büro findet Héctor schließlich ein Telegramm Taibos: »Fui a preguntarle. Paco Ignacio« (AN, 124). Der Schriftsteller im Roman suchte

62 " [...] hay como una idea de tocar a la sociedad mexicana desde varios angulados, de proponer una especie de lógica de resistencia del ciudadano contra el sistema, una literatura de acción « (AN, 41).

63 Héctor meint denn auch: »Ha habido denuncias en los periódicos contra casi todos los jefes policíacos de la ciudad de México, algunas revistas hasta campaña hicieron. Y nada, no pasa nada. La verdad creo que por el lado de la presión en la prensa poco se puede hacer « $(\mathrm{AN}, 106)$; »[s]abía que cuando llegara al final, si llegaba, se iba a encontrar con una pared que impediría la justicia« (AN, $50)$.

64 So beantwortet Taibo die Frage nach dem Detektiv der 90er Jahre wie folgt: „¿En México? Surrealista, se mueve entre una doble tensión. La tensión de la atroz información que la realidad te proporciona todos los dias sobre la violencia policíaca y el abuso del poder y una propuesta neorromántica de ajustar la realidad a partir de crear justicia en el acto individual colaborando con lo social«, in: Juan C. Ramírez / Verónica Rodríguez Sifontes (1992: 42). Taibo vermerkt über die widersprüchliche Einstellung seines Detektivs: „Belascoarán cree en la terquedad y en la tenacidad. Cree que no existe ciencia ninguna que pueda aproximar a un mexicano a descubrir la verdad [...]. Hay una tendencia a la falsedad informativa en México, ¿no? En este sentido esta inercia hacia la mentira ha probado que un detective es una especie de reencontrador de la verdad que lo hace a partir de la tenacidad«, ibid., p. 43. 
wie der Detektiv nach der Wahrheit, und er musste hierfür mit dem Leben bezahlen. Das mexikanische System hat sich erneut höchst effektiv jener Männer entledigt, die sein Funktionieren zu stören drohten. Taibo spielt ein letztes Mal mit den Möglichkeiten einer Vermischung von Fakt und Fiktion, indem er sich selbst im Roman sterben lässt. Das Ende von Unamunos Niebla, in dem der Protagonist stirbt und der Autor konsequenterweise weiterlebt, wird ironisch zitiert und in absurd anmutender Weise auf den Kopf gestellt. Taibos Roman endet somit ohne Autor, oder aber der Autor des Romans ist ein anderer als Taibo. Zwar konnte Héctor Belascoarán Shayne das Rätsel der Ermordung Costas lösen, aber das von dem mexikanischen Kriminalautor aufgeworfene Rätsel um die Grenzziehung zwischen Realität und Fiktion sowie ihre inner- und außerliterarischen Folgen besteht weiter.

\section{Bibliographie}

\section{Literarische Werke und andere Quellen}

Aristoteles (1994): Poetik, griechisch / deutsch, übers. u. hrsg. v. Manfred Fuhrmann, Stuttgart: Reclam.

Constitución Politica de los Estados Unidos Mexicanos. Constitution Politique des Etats Unis du Mexique. Political Constitution of the Mexican United States (1962), Mexiko: Cámara de Senadores.

Monsiváis, Carlos (1973): »Ustedes que jamás han sido asesinados«, Revista de la Universidad de México 28: 7, pp. 1-11.

Paz, Octavio ( ${ }^{2} 1991$ [1950]): El laberinto de la soledad, Mexiko: Fondo de Cultura Económica.

Reyes, Alfonso (1989): »Algo más sobre la novela detectivesca«, in: id.: Obras Completas, México: Fondo de Cultura Económica, Bd. 22, pp. 412-417.

Reyes, Alfonso (1959): »Sobre la novela policial«, in: id.: Obras Completas, Mexiko: Fondo de Cultura Económica, Bd. 9, pp. 457-461.

Reyes, Alfonso (1989): »Un gran policía de antaño«, in: id.: Obras Completas, Mexiko: Fondo de Cultura Económica, Bd. 22, pp. 417-420.

Sábato, Ernesto (1973): "Heterodoxia«, in: id.: Hombres y engranajes. Heterodoxia, Madrid: Alianza, pp. 95-198.

Simenon, Georges (1950): Les mémoires de Maigret, Paris: Presses de la Cité.

Taibo II, Paco Ignacio (1994 [1985]): Algunas nubes, Mexiko: Mortiz.

Taibo II, Paco Ignacio (1998 [1977]): Cosa fácil, Mexiko: Planeta.

Taibo II, Paco Ignacio (1994 [1990]): Cuatro manos, Vitoria: Ikusager.

Taibo II, Paco Ignacio (1976): Días de combate: una historia de Belascoarán Shayne, Mexiko: Grijalbo.

Taibo II, Paco Ignacio (1994 [1982]): Héroes convocados, Mexiko: Roca.

Taibo II, Paco Ignacio (1992): La lejanía del tesoro, Mexiko: Mortiz.

Taibo II, Paco Ignacio ( ${ }^{2} 1991$ [1987]): La vida misma, Mexiko: Planeta. 
Taibo II, Paco Ignacio (1985 [1981]): No habrá final feliz, Mexiko: Planeta.

Taibo II, Paco Ignacio (1989): Regreso a la misma ciudad y bajo la lluvia, Mexiko: Planeta.

Forschungsliteratur

Argüelles, Juan Domingo (1990): »El policíaco mexicano: un género hecho con un autor y terquedad. Entrevista con Paco Ignacio Taibo II «, Tierra Adentro 49, pp. 1315.

Braham, Persephone (1997): »Violence and Patriotism: \La Novela Negra< from Chester Himes to Paco Ignacio Taibo II«, Journal of American Culture 20: 2, pp. 159169.

Claudín, Víctor (1985): „Vázquez Montalbán y la novela policiaca española«, Cuadernos Hispanoamericanos 416, pp. 157-166.

Colmeiro, José F. (1992): »Posmodernidad, posfranquismo y novela policíaca«, España Contemporánea 5, pp. 27-39.

Corona, Martín (1998): „De arcángeles herejes, derrotas y lecciones habló Paco Ignacio Taibo II «, http://asesores.uv.mx/Gaceta/Sep98/Quenave1.htm (03.02.2001).

Díaz, César E. (1973): La novela policiaca. Síntesis histórica a través de sus autores, sus personajes y sus obras, Barcelona: Acervo.

Duncan, Cynthia (1991): »Exploding the Myth of Law and Order: Detective Fiction in Mexico as an Ideological Statement«, Journal of Interdisciplinary Studies / Cuadernos Interdisciplinarios de Estudios Literarios 2, pp. 197-216.

Ette, Ottmar (1994): "Asymmetrie der Beziehungen. Zehn Thesen zum Dialog der Literaturen Lateinamerikas und Europas«, in: Scharlau, Birgit (Hrsg.): Lateinamerika denken. Kulturtheoretische Grenzgänge zwischen Moderne und Postmoderne, Tübingen: Narr, pp. 297-326.

Firth, Felicity (1982): »The Mask as Face and the Face as Mask: Some of Pirandello's Variations on the Theme of Personal Appearance«, Yearbook of the British Pirandello Society 2, pp.1-27.

Fricke, Dietmar (1977): »Der Roman Policier in Literaturwissenschaft und Fachdidaktik - Neue Perspektiven für das Fach Romanistik«, in: Schröder, Konrad / Weller, Franz R. (Hrsg.): Literatur im Fremdsprachunterricht. Beiträge zur Theorie des Literaturunterrichts und zur Praxis der Literaturvermittlung im Fremdsprachenunterricht, Frankfurt am Main: Diesterweg, pp. 250-272.

Görling, Reinhold (1997): Heterotopia. Lektüren einer interkulturellen Literaturwissenschaft, München: Fink.

Hölz, Karl (1988): »Pirandello und die literarische Tradition der Lüge - Zur Metamorphose eines Motivs «, in: Rössner, Michael / Hausmann, Frank-Rutger (Hrsg.): Theatralisierung der Wirklichkeit und Wirklichkeit des Theaters, Bonn: Romanistischer Verlag, pp. 48-83.

Ingenschay, Dieter / Neuschäfer, Hans-Jörg (Hrsg.) (1991): Aufbrüche - Die Literatur Spaniens seit 1975, Berlin: Tranvía.

Landfester, Ulrike (1990): „Die Spuren des Lesers: Überlegungen zur intertextuellen Rezeption im modernen deutschen Kriminalroman«, Poetica 22: 3-4, pp. 413-435.

Marsch, Edgar (1972): Die Kriminalerzählung. Theorie - Geschichte - Analyse, München: Winkler.

Martínez, José L. / Domínguez Michael, Christopher (1995): La literatura mexicana del siglo $X X$, Mexiko: Consejo Nacional para la Cultura y las Artes. 
Meunier, Jacques (1993): »Viva Paco«, Le Monde 22.1.1993, p. 32.

Molinet, Pablo María (1997): »Entrevista con Paco Ignacio Taibo II. Los apaches civilizadores«, Memoria 106 (Dez.), http://memoria.com.mx/106/106mem04.html (03.02.2001).

Narcejac, Thomas (1975): Une machine à lire: le roman policier, Paris: Denoël.

Neuschäfer, Hans-Jörg (1976): Populärromane im 19. Jahrhundert von Dumas bis Zola, München: Fink.

Paz Balibrea Enríquez, Mari (1996): »Paco Ignacio Taibo II y la reconstrucción del espacio cultural mexicano«, Confluencia 12: 1, pp. 38-55.

Plans, Juan José (1969): »Historia de la novela policíaca«, Cuadernos Hispanoamericanos 79, pp. 421-443 und pp. 675-699.

Rama, Ángel (1982): Transculturación narrativa en América Latina, Mexiko: Siglo XXI.

Ramírez, Juan C. / Rodríguez Sifontes, Verónica (1992): »Paco Ignacio Taibo II: la lógica de la terquedad o la variante mexicana de una locura «, Mester 21: 1, pp. 41-50.

Revueltas, Eugenia (1987): »La novela policial en México y en Cuba«, Cuadernos Americanos 1 , pp. 102-120.

Schulz-Buschhaus, Ulrich (1975): Formen und Ideologien des Kriminalromans. Ein gattungsgeschichtlicher Essay, Frankfurt am Main: Athenaion.

Schulz-Buschhaus, Ulrich (1991): »Das System und der Zufall. Zur Parodie des Detektivromans bei Jorge Luis Borges«, in: Pfeiffer, Erna (Hrsg.): Canticum Ibericum: Neuere spanische, portugiesische und lateinamerikanische Literatur im Spiegel von Interpretation und Übersetzung, Frankfurt am Main: Vervuert, pp. 382-396.

Schulz-Buschhaus, Ulrich (1997): »Funktionen des Kriminalromans in der post-avantgardistischen Erzählliteratur«, in: id. / Stierle, Karlheinz (Hrsg.): Projekte des Romans nach der Moderne, München: Fink, pp. 331-368.

Schweighaeuser, Jean-Paul (1984): Le roman noir français, Paris: PUF.

Semana Negra en Gijón, http://pp.terra.com.mx/ mschwarz/snes.html (03.02.2001).

Simpson, Amelia S. (1990): Detective Fiction from Latin America, London / Toronto.

Stavans, Ilán (1993): Antihéroes. México y su novela policial, Mexiko: Mortiz.

Stavans, Ilán (1994): »A Brief (Happy) Talk with Paco Ignacio Taibo II«, The Literary Review, pp. 34-37.

Sterr, Albert (1997): ")Ich mag die Literatur, in der die Reflexion mit der Aktion eng verbunden istc. Ein Gespräch mit Paco Ignacio Taibo II., Krimi-Autor aus Mexiko«, http://www.oeko-net.de/kommune/kommune3-97/ktaiblit.html (03.02.2001).

Strosetzki, Christoph (1991): Miguel de Cervantes. Epoche - Werk - Wirkung, München: Beck.

Taibo II, Paco Ignacio (1986): »La >otra< novela policíaca«, Los Cuadernos del Norte 7 : 41 , pp. 36-41.

Taibo II, Paco Ignacio (1991): »Paco Ignacio Taibo II speaks out«, Review: Latinamerican Literature and Arts, pp. 6-9.

Tlatelpas, José (1997): »Entrevista a Paco Ignacio Taibo II«, La Guirnalda Polar 2: 13 (Nov.), http://www.ven.bc.ca/spcw/13page.htm (03.02.2001).

Torres, Vicente Francisco (1985): "La novela policíaca mexicana«, La palabra y el hombre $53 / 54$, pp. $37-42$.

Žmegač, Viktor (1971): »Vorwort«, in: id. (Hrsg.): Der wohltemperierte Mord. Zur Theorie und Geschichte des Detektivromans, Frankfurt am Main: Athenäum, pp. 78. 